\title{
Glutathione S-transferase Activity in Diagnostic Pathology
}

\section{Chikezie PC*}

Department of Biochemistry, Imo State University, Owerri, Nigeria

\begin{abstract}
Glutathione S-transferase (GST) is a generic term that describes a class of proteins involved in phase-II detoxification of endogenous compounds and xenobiotics. Regulation and function of GSTs have influences on cell growth, oxidative stress, as well as disease progression and prevention. Although not routinely assayed in clinical laboratories, the present review highlighted the application of GST activity in diagnostic pathology. Human GSTs are divided into three main families, namely, the cytosolic, mitochondrial and membranebound microsomal GSTs. The expression of GST isoforms in biologic systems may well be of relevance from a clinical and toxicity standpoints and applies in the renewed efforts in eradication and control of parasitic infections. A survey of frequency of polymorphism and measure of GST activity among human population groups are reliable and valuable diagnostic tools. The reliability of GST activity in diagnostic pathology is underscored in pathologic conditions/disorders whose etiologies are associated with overwhelming levels of oxidative stress and failure of GST-mediated detoxification mechanisms.
\end{abstract}

Keywords: Diagnosis; Glutathione S-transferases; Isoforms; Pathology; Polymorphisms

\section{Introduction}

Glutathione $S$-transferase (GST; EC: 2.5.1.18) is a generic term that describes a class of proteins involved in phase-II detoxification of endogenous compounds and xenobiotics [1]. GST isoenzymes exhibit differential but overlapping substrate specificity, in which the catalytic efficiency of the individual isoenzyme dictates the extent to which biotransformation of the substrate occurs [2-5]. The GST-mediated detoxification pathway ensures cellular protection from environmental insults and oxidative stress, though it has also been implicated in cellular resistance to drugs [5-11]. For instance, overexpression of GSTs in the endothelium serve to protect soft tissues against oxidative damage from aldehydes such as 4-hydroxynonenal (4-HNE) [12] and neuroprotection of photoreceptors is connected with GST-mediated reduction of oxidative stress in retinal explants from $r d 1 / r d 1$ mice [13].

Much attention was focused on thiol-mediated antioxidant/ detoxification proteins since the 1970s [14]. Early reports showed that GSTs isolated and characterized from rat and human liver [3,15-18], pigeon, locust gut, housefly and other sources [16] have common properties to bind to reduced glutathione (GSH) and wide variety of hydrophobic compounds. The structural dimensions of the GSTs have been exhaustively described [14]. Overall, regulation and function of GSTs have influences on cell growth, oxidative stress, as well as disease progression and prevention [5]. GSTs are divided into two distinct family members, the membrane-bound microsomal and cytosolic family members. The expression or activities of specific GST isoforms in various biological systems are closely associated with different clinical conditions and toxicity outcomes. Thus, surveying the frequency of polymorphism or measurement of GST activity among human population groups are reliable and valuable diagnostic tools. Although not routinely assayed in clinical laboratories, the present review highlighted the application of GST activity in diagnostic pathology because of the indispensable role of the enzyme in cellular functional integrity.

\section{Evidence acquisition}

Scientific search engines such as PubMed, Pubget, Medline, EMBASE, Google Scholar, ScienceDirect and SpringerLink were used to retrieve online publications from 1969 to 2015. Keywords such as 'Plasmodium', 'malaria', 'glutathione detoxification', 'ligandins' 'oncology' 'polymorphisms', 'metabolic disorders', 'hepatobiliary' etc. were used to collate relevant articles. The results were then crossreferenced to generate a total number of 125 references cited in this review.

\section{Functions of glutathione $S$-transferases}

The functions of GSTs have been classified into two general categories $[19,20]$. As intracellular binding proteins [2,21,22], GSTs function on a broad scale in solubilizing and transport of substances much as the extracellular functions of albumin described elsewhere $[23,24]$. The GST from rat liver, designated as transferase $B$, has been shown to be identical to the bilirubin binding protein or 'ligandins' [25]. Although ligandins have high affinity for endogenous compounds such as bile acids, haemin, bilirubin, fatty acids and steroids [16,18,22], whose conjugates are eventually sequestered [26], the bound GSTs are devoid of catalytic processing and do not form glutathione conjugates with their substrates [18,27]. Another specific protective role of GST as ligandin is the specific binding of intra-erythrocyte GSTP1-1 isoform to Jun-kinase, a pro-apoptotic enzyme that becomes inactive when bound to GST $[26,28]$.

The second major function is the protection of cellular components $[29,30]$ by the preferential reaction of electrophilic agents with GSH through the enzymatic action of GSTs, and thereby prevents the reaction of electrophiles with cellular nucleophiles. The enzyme may also detoxify certain extremely reactive substances by direct covalent binding to electrophilic agents $[1,22,31]$. For the most part, GSTs catalyze the conjugation of electrophilic groups of hydrophobic drugs and xenobiotics to form glutathione-thioethers [32]. These thioethers are converted to mercapturic acid by the sequential actions of $\gamma$-glutamyl transpeptidase, depeptidase and $\mathrm{N}$-acetylase $[2,15,33]$ prior to the eventual elimination of the hydrophilic conjugates.

Reactive oxygen and nitrogen species (ROS/RNS) can alter the

*Corresponding author: Chikezie PC, Department of Biochemistry, Imo State University, Owerri, Nigeria, Tel: +2348038935327; E-mail: p_chikezie@yahoo.com

Received September 17, 2015; Accepted October 08, 2015; Published October 10,2015

Citation: Chikezie PC (2015) Glutathione S-transferase Activity in Diagnostic Pathology. Metabolomics 5: 153. doi:10.4172/2153-0769.1000153

Copyright: () 2015 Chikezie PC. This is an open-access article distributed under the terms of the Creative Commons Attribution License, which permits unrestricted use, distribution, and reproduction in any medium, provided the original author and source are credited. 
structure and/or function of number proteins by their selective modification of proteins such as enzymes, receptors, structural proteins, transcription factors and transport proteins and may also alter a variety of protein-protein interactions. Additionally, raised cellular ROS/RNS levels promote peroxidation of structural and particulate lipids such as those present in biomembranes and lipoproteins, which form the molecular basis of several pathologic conditions. The GSTs participate in protecting the cell against deleterious actions of ROS/ RNS by promoting redox homeostasis through neutralization of excess reactive electrophiles, whose chemical actions elicit numerous signaling cascades associated with cell proliferation, inflammatory responses, apoptosis and senescence [14]. In parasitic infections, e.g. malaria, GST is a component of the thiol-mediated antioxidant detoxification systems of Plasmodium that are required for survival of the malarial parasite in hyperoxidative intracellular environment it encounters during its development in mammalian and insect hosts [7,34-36]. Also, physiochemical analyses of the gastrointestinal blood-feeding nematode Haemonchus contortus showed that the parasite harbors GST of high-affinity for hematin, which represented the parasite adaptation to blood or tissue feeding from the host [37]. Helminth GSTs participate in detoxification of lipid hydroperoxides and carbonyl cytotoxins produced by oxygen-reactive intermediates [38]. Accordingly, Plasmodium falciparum, H. contortus and helminth GSTs have been suggested to be attractive targets for new anti-parasitic drugs and vaccine discovery [37-39].

\section{Molecular dimensions of glutathione $S$-transferases}

Human GSTs are divided into three main families, namely, the cytosolic, mitochondrial and membrane-bound microsomal GSTs $[5,8]$. For instance, the cytosolic human GSTP1-1 isoform ( $h$ GSTP1-1), which is a major intra-erythrocyte transferase- representing $95 \%$ of its entire GST pool $[20,40]$, is a homodimeric intracellular protein of about $46 \mathrm{kDa}$ expressed in different organs and cell types [26]. Specifically, the molecular mass of the cytosolic GSTs monomers are in the range of $22-29 \mathrm{KDa}$ and exhibit activity over a wide variety of substrates with considerable overlap $[1,2,4]$. Each monomer contains an active site with two sub-sites: a less conserved $\mathrm{H}$ site for binding to varieties of hydrophobic substrates and a highly conserved G site for GSH binding [14]. The general mammalian cytosolic GSTs encompass dissimilar dimeric isoenzymes within molecular mass of 45-55 KDa, which have been assigned to at least four generic classes, namely, $\alpha-, \mu$-, $\pi-$, and $\Theta-G S T s[2,3,26,41,42]$ in addition to the K- $\Omega$-, $\delta$-GSTs $[5,43]$, whereas the membrane bound microsomal GSTs are component of another classified proteins, the so called membrane-associated proteins in eicosanoid and glutathione metabolism (MAPEG) [4446]. The MAPEG entities are involved in endogenous metabolism of leukotrienes- and prostaglandins-derived mediators of pain, fever, and inflammation as well as in biotransformation and detoxification of electrophilic substances $[14,46]$. Using electron crystallography, the molecular dimensions of microsomal GST has been established as well as identification of critical amino acid residues that are responsible for intramolecular or intermolecular contacts in stabilizing the active site, which applies in interpreting the structure-function relationship for similar MAPEG entities [46].

\section{Isoforms}

The human liver cytosolic GST classes are $\alpha-, \beta-, \gamma^{-}, \delta-, \quad \xi-[25]$ and Ź-GSTs [47]. These six classes of GST originate from six different chromosomes but share $\sim 30 \%$ sequence identity [14]. GST isoforms have cell specific distribution (e.g. GSTA1 in hepatocytes and GSTP1 in the biliary tract of the human liver) [48]. The GSTP1 isoform exists in the human erythrocytes [49], which is different from the GSTs present in the human liver [1,17]. Although, all GST isozymes have two domains and similar topologies, $<10 \%$ of the protein is strictly conserved [14]. The occurrence of genetic polymorphisms in the various classes of cytosolic GSTs have been described and linked to the prevalence of incidences of cancers, parasitic infections, diverse pathologic conditions and disorders $[8,10,14,50-52]$. For instance, polymorphisms in the GSTP1 gene arise from nucleotide transitions that change codon 105 from Ile to Val and codon 114 from Ala to Val, thus generating four GSTP1 alleles: wildtype GSTP1*A (Ile105 $\rightarrow$ Ala114), GSTP1* $B$ (Val105 $\rightarrow$ Ala114), GSTP ${ }^{*} C$ $($ Val105 $\rightarrow$ Val114) and GSTP1*D (Ile105 $\rightarrow$ Val114) [14,53]. Evaluation of three GST isoforms-GSTM1, GSTP1 and GSTT1 in patients presenting acute respiratory distress syndrome showed an association between GSTM1-null, GSTM1- and GSTT1-double null polymorphisms with increased incidence of mortality [10]. Additionally, individuals with the GSTM1-null or GSTT1-null genotypes display absence of enzymatic activity and are believed to be at higher risk to cytotoxic effects of a wide spectrum of xenobiotics and carcinogens [54]. Structural analyses of these GST variants showed steric alteration at the substrate-binding site of the enzyme without affecting the GSH binding site, which correspondingly implies that GSH binding affinity are not affected, whereas significant alterations at the substrate binding domain occur [55]. As a consequence of GST polymorphisms, enzymatic activities of the GST variants are significantly altered.

\section{Parasitic infections}

The level of parasite GST activity serves to define the capability of the organism to withstand anti-parasitic drugs. For instance, in chloroquine-resistant strains of rodent (Plasmodium berghei, P. yoelii) and human malarial parasites, GST activity was significantly raised when compared with the sensitive strains and was directly related to drug pressure on resistant parasite [56]. Alterations in serum or plasma levels of GST activity and its GSH cofactor are diagnostic of parasitic infection in susceptible individuals [57,58]. According to Sohail et al., [57] the mean activity of GST in serum and plasma of patients infected with $P$. vivax were less (6.43 and $5.65 \mathrm{IU} / \mathrm{L}$ respectively) than the corresponding healthy subjects (11.65 and 10.09 IU/L respectively). They further noted that the decreased GST activity served to protect the host erythrocytes against the invading malarial parasite by up-regulating oxidative defense mechanisms. In the same vein, previous reports have shown that antioxidants such as GSH, catalase and $\alpha$-tocopherol were lower in patients with malaria $[51,59]$ or visceral Leishmaniasis [58] than the control groups. Consequently, low levels of plasma GST activity may elicit the accumulation of ROS/ RNS because of decreased antioxidant scavenging capacities with attendant membrane lipid peroxidation and oxidation of haemoglobin to methaemoglobin [58]. According to Chikezie et al., [60], outcome of comparative study of GST activity of human erythrocyte genotypes infected with $P$. falciparum suggested that GST activity was a reliable biomarker and possesses promising rational for diagnostic potential in malaria.

In another investigation, Kavishe et al., [51] reported that polymorphisms in GST genes were associated with susceptibility and severity P. falciparum malaria in Cameroon population. In their study, the frequencies of polymorphisms in GSTM1, GSTT1, and GSTP1 in DNA of 138 children from Cameroon were analyzed using multiplex polymerase chain reaction (mPCR) assay, whereas that of GSTP1 was done using polymerase chain reaction-restriction fragment 
length polymorphism (PCR-RFLP) assay. The findings indicated that malarious subjects with complications were more often of the GSTM1null genotype (58-64\%) as against those with uncomplicated malaria (32\%), a difference that was statistically significant $\left(x^{2}=6.7 ; p=0.05\right.$ : $x^{2}=3.5 ; p=0.031$ ). Thus, there was an established relationship between the frequencies of GST polymorphisms and levels of severity and complication of malaria in children.

\section{Oncology}

The GST isoforms conjugate GSH to electrophilic carcinogens and there are incontrovertible evidence that underscores the relationship between GST polymorphism and incidence of development of cancers of the gastrointestinal tract, ovaries, prostate, and esophagus in selected mammalian population [9,61-67]. Furthermore, the level of expression of GST could provide useful diagnostic parameter in carcinoma of the breast [68] and bladder [69,70]. Evidence from molecular epidemiological studies showed that individual susceptibility to cancer is mediated by both genetic and environmental factors. For instance, individuals who have both GSTT1- and GSTM1-null genotypes are more predisposed to acute myeloid leukemia [71] as well as oral leukoplakia risk as a result of carcinogenic intermediates derived from or generated during habitual chewing of betel quid/tobacco [72,73].

In oncology, the GSTP1 isoform, which is the most ubiquitous and prevalent GST in non-hepatic tissues, are present in raised levels in many tumors, particularly, that of the ovarian, non-small cell lung, breast, colon, pancreas and lymphomas as well as in wide range of drug resistant cell lines [14,74]. In specific terms, Bostwick et al., [9] reported differential expression of GSTA1, GSTM1 and GSTP1 isoforms in benign prostate, prostatic intraepithelial neoplasia, and prostatic adenocarcinoma. The study observed that consistent reduction or loss of expression of all subclasses of GST could engender the progression of prostatic neoplasia from benign epithelium to high-grade prostatic intraepithelial neoplasia and carcinoma. Another investigation according to Chen and Lin, [63] showed that raised levels of GSTA1, GSTM1 and GSTP1 activities confirmed oral epithelial dysplasias (OEDs) and squamous cell carcinomas in human. Specifically, total GST activities of the three isoforms were significantly elevated in mild OED, moderate OED, severe OED and squamous cell carcinoma when compared with that from normal buccal mucosa [63]. They further noted that GSTP1 was the major isoform in the cytosolic fraction of oral mucosa and severity of OED was connected with the development squamous cell carcinoma, which appeared to increase correspondingly with increased level of GSTP1 activity.

In another study, Naidu et al., [64] described the implication of total GST activity levels and GSTP1 protein expression in paired samples of colorectal cancer, adenoma and normal mucosa from a total of thirteen patients using spectrophotometric methods. The study showed that GST activity was significantly raised in both colorectal cancer and adenomas when compared with normal colonic tissue-an indication that raised levels of GST activity may serve as a useful diagnostic index for colonic neoplasia in humans. Conversely, in the reports of Szarka et al., [61] significant low levels of GST activity was noted in blood lymphocytes from high-risk colorectal cancer individuals when compared with blood lymphocytes from control individuals $(p<$ or $=$ 0.004). However, no association was observed between the frequency of GSTM1 phenotype and risk of colorectal cancer and high-risk individuals unable to express GSTM1 had lower levels of GST activity than those from control subjects $(p<$ or $=0.006)$ [61]. There are evidence to suggest an association between GSTM1-null genotype and increased risk of gastric cancer [67]. Using case-control study approach involving PCR-based assays, Casson et al., [66] hypothesized that polymorphisms of microsomal epoxide hydroxylase and GST genes modulated the susceptibility to esophageal adenocarcinoma (EADC) associated with smoking, which showed a strong statistical association between smoking and risk for EADC in individuals.

There are contradictory reports on the use of GST activity as a diagnostic index in the monitor and ascertaining therapeutic benefits following treatment of ovarian cancer patients. Wrigley et al., [62] used immunohistochemistry and Western blot methods to evaluate the correlation between GSTA1, GSTM1 and GSTP1 isoforms activities in association with clinicopathological features and response to treatment in ovarian cancer, in which they noted that none of the GST isoenzyme levels were significantly correlated with response to treatment. In a related study, serum GST activity of untreated patients with malignant ovarian tumors was significantly raised when compared with those of healthy individuals and patients with benign ovarian tumors [65]. From their study, Akçay et al., [65] further suggested that a monitor of GST activity was important in diagnostic and therapeutic approach to detection and treatment of ovarian cancer.

\section{Hepatobiliary damage}

Patients with hepatocellular damage exhibit elevated plasma GST activity [75,76]. Although serum GSTA1 activity is a sensitive biomarker of liver injury [77,78], studies according to Thorburn et al., [79] showed that it was not useful in ascertaining the level of liver inflammation in chronic hepatitis $\mathrm{C}$ infection, though the data may be of more value than ALT in monitoring response to treatment with a-interferon. Nevertheless, reports of Yukihiko et al., [77] noted that the degree of correlation between serum GST and ALT or AST was high in acute hepatitis, with ALT or AST exceeding $200 \mathrm{IU} / \mathrm{L}$ in fulminant hepatitis, primary hepatoma and gall stones, whereas in chronic hepatitis and liver cirrhosis the correlation was low. Furthermore, serum GST exhibit shooter half-life than ALT or AST in the blood, which suggest new and unique information for the diagnosis of acute liver diseases. A recent clinical survey by Weng et al., [80] established the association between drug hepatotoxicity and daily dose, liver metabolism and lipophilicity of oral medications. They noted that high oral dose of drugs and extensive hepatic GST mediated drug metabolism are independent but not synergistic risk factor for oral drug to induce hepatic injury, which correlated with significant plasma ALT/AST elevation. The findings have further confirmed the potentials of applying GST activity in prediction and monitoring of drug toxicity. Nevertheless, earlier reports by Rattenbury et al., [81] had noted that measurement of GSTB1 isoform in serum using radioimmunoassay technique may be a better predictor of hepatic dysfunction in cystic fibrosis than conventional liver function tests.

\section{Diabetes mellitus and metabolic disorders}

The GSTs, in concert with antioxidant systems, modulate oxidative stress associated with diabetes mellitus (DM). For instance, mitochondria-specific GSTK isoform has also been implicated in obesity, diabetes and related metabolic disorders [5]. Conversely, GSTP1isoleucine/valine and valine/valine alleles, alone or in association with GSTM1-null and GSTT1-present genotypes, does not influence the risk of susceptibility to development of metabolic disorders [82]. Although the studies according to Santl et al., [83] did not find a significant association between GSTM1 and GSTP1 polymorphisms and carotid atherosclerosis, the GSTT1-null genotype and GSTT1-null/GSTM1null haplotype might be potential determinants of susceptibility to advanced atherosclerosis in patients with T2DM. 
Using a 2-year change of the common carotid intima media thickness (CCA-IMT), which was measured using B-mode ultrasonography, de Waart et al., [84] suggested that smokers who expressed the GSTM1null genotype, and thus lacking this functional detoxifying enzyme, developed progression of atherosclerosis in a significantly $(p=0.02)$ increased rate when compared with smokers with GSTM1-positive genotype. A related study by Park et al., [85] showed that GSTT1null genotype might be connected with carotid atherosclerosis related to rheumatoid arthritis in Korean postmenopausal women without histories of smoking. Furthermore, the protective role of GST activity against vascular cell injury was reported by Xu et al., [86], in which they established that $h$ GSTA4-4 overexpression protected the integrity of vessel wall epithelium from oxidative injury, as earlier mentioned [12], and attenuated transplant arteriosclerosis.

Studies have shown that silencing the GSTA4 gene resulted in mitochondrial dysfunction, as was also observed in mice that exhibited GSTA4-null genotype, which contributed to insulin resistance in Type 2 DM (T2DM) [5]. Accordingly, mPCR assay of GST isoforms has established a relationship between GST gene polymorphism and DM [87-89]. In specific instance, the GSTM1-null/GSTT1-null genotypes contributed to the clinical course of T2DM patients and increased susceptibility to T2DM in Brazilian population [88], whereas GSTT1present genotype conferred protection against the development of a T2DM [90-92]. Another study by Amer et al., [87] showed that the frequency of the Val allele in exon 5 of the GSTP1 gene in patients with T2DM was $15.2 \%$ as against that observed in healthy controls (9.6\%); and was statistically significant $(p=0.03)$ when compared with Ile allele carriers. They further noted that the presence of GSTP1 heterozygous mutant allele Ile/Val in Egyptian population was more common in subjects with T2DM than in the control group $(30.4 \%$ and $19.2 \%$, respectively; $p=0.02$ ). Recent findings of Rasheed et al., [89] have corroborated the association of GSTM1 and GSTT1 gene polymorphisms with T2DM in Iraqi patients.

Cross-sectional study by Velladath et al., [93] showed a weak positive correlation between erythrocyte GST activity and $\mathrm{HbA}_{1 \mathrm{c}}$ concentration in diabetic patients $(r=0.239, p=0.089)$. Although the study appeared to suggest that GST activity is associated with formation of $\mathrm{HbA}_{1 c}$ in diabetic patients, chronicity of the disease along with treatment modalities that might have played a significant role in the outcome of the study [93].

\section{Reproductive system disorders}

The GSTM1- and GSTT1-null genotypes have been associated with male infertility [94] and female infertility [95,96]. The high frequency of homozygotes GSTM1 gene deletion among patients with endometriosis suggests a possible contribution of environmental toxins in the pathogenesis of this disease due to the absence or low activity of GSTM1 [50]. Many environmental and genetic etiological factors that are responsible for the occurrence of early pregnancy loss have been controversially discussed. However, the frequencies of polymorphisms in phase-I drug metabolizing enzymes (cytochrome P450 genes) and phase-II detoxification enzymes (e.g., GST genes) may contribute to the development of pre-eclampsia [96]. The occurrence of the GSTP1b-1b genotype -a non-functional GSTM1 or GSTT1 allele has been linked to relatively lower GSTP1 activity with consequential impaired placental detoxification capability, which represents a risk factor for recurrent early pregnancy loss [97]. In concord with earlier investigation by Suryanarayana et al., [98], studies according to Polimanti et al., [99] and Nair et al., [100] reported that the expression of GSTA1- and GSTM1-positive/null genotypes in Italian women and
GSTT1- and GSTM1-null genotypes in Indian women, respectively were connected with the incidence of reoccurring pregnancy loss. The findings particularly noted that the $-69 \mathrm{~T}$ allele in the GSTA1 gene may be considered as a predisposing factor of recurrent miscarriage.

Chandra et al., [101] recently reported that there was a definite association between maternal GSTT1- and GSTM1-null genotypes activities and higher incidence $(p=0.001)$ of fetal growth restriction (IFGR), which correlated with fetal weight. They further noted that cumulative levels of GST activity in mothers giving birth to IFGR babies was about $50 \%$ of the values found in the control group $(p<0.001)$. Measurement of GST activity in neonates is a useful biomarker of oxidative stress and evaluation of protective treatment trials at birth [102].

Measurement of human placental GST activity served to ascertain general health status of newborn in radioactivity-contaminated and chemically polluted areas of Ukraine and Belarus [103]. The findings showed that newborns with the most compromised health status displayed the greatest down-regulation of GST activity=144-162 $\mathrm{mU} \mathrm{mg}$ protein ${ }^{-1}$ as against newborn GST activity $=258-395 \mathrm{mU} \mathrm{mg}$ protein ${ }^{-1}$ in uncontaminated and pollution free areas.

Finally, GST activity is a reliable biomarker of oxidative stress in liver, kidney and testes, and more specifically, a measure to ascertain acute toxic effects of zearalenone, which is a non-steroidal estrogenic mycotoxin produced by several species of Fusarium, on reproductive system of adult male Swiss albino mice [104]. A related study by Quinn et al., [105] showed that resistance of mouse liver to aflatoxin B1 (AFB1) could be traced to single constitutive GST isoenzyme with a relatively high activity toward DNA-binding metabolites of AFB1.

\section{Alcoholism and substance abuse}

GSTM1 genotype in human population may be associated with a greater susceptibility to alcohol-induced spermatogenesis disorders, whereas the occurrence of GST M1-null and GSTP1-null genotypes are associated with alcoholic liver disease [106-109]. Expectedly, alcoholdependent subjects exhibited significantly lower $(p<0.001)$ GST activity in blood and saliva when compared with control subjects due to elevated oxidative stress and impairment of antioxidants in alcoholism [110]. Nevertheless, the investigation revealed a significant increase $(p<0.001)$ in GST activity, with near control values, following alcohol withdrawal.

According to the reports of La Vignera et al., [111], the frequency of GSTM1 genotype in heavy drinkers with normal spermatogenesis differed from that of corresponding moderate drinkers, whereas the frequency of GSTM1 genotype in heavy drinkers with disorders of spermatogenesis was similar to moderate drinkers with or without disorders of spermatogenesis. Additionally, since the study of Pajarinen et al., [106] noted that $>20 \%$ of heavy drinkers had normal spermatogenesis; it was an indication that the GSTM1 genotype exerts a protective effects on alcohol-induced spermatogenesis disorders.

Studies involving the role GSH and redox signaling in substance abuse showed that chronic use of drugs, such as cocaine and methamphetamine lead to the formation of ROS/RNS and alterations in GSH and redox homeostasis [112]. As expected, GST activity exerted protective role during substance abuse and intoxication. The hazardous effect of heroin intoxication on different regions of the brain was evaluated using real time polymerase chain reaction (RT-PCR) in the reports of Gutowicz et al., [113], in which they noted that the protective effect of GST was observed to be lower in brain stem than in brain cortex or hippocampus. 


\section{Renal injury and uremia}

Localization of GSTA1 isoform in specific parts of the proximal renal tubule, which is readily released into the urine following injury, is used an excellent biomarker for proteinuria [114]. Over-expression of GST by $>50 \%$ in erythrocytes of patients with chronic renal failure and uremia $[20,26,115,116]$ and early diagnosis for uremia-related complications [117], which have received immense attention and documentations. Galli et al., [20] reported that over-expression of GST activity was the consequence of an increased expression of the protein rather than a kinetic modulation of the enzyme. In these studies, the significant increase in erythrocyte GST activity in pre-dialysis patients showed a positive correlation with the disease severity. Furthermore, the stable level of erythrocyte GST activity, during the life span of the erythrocyte, provides a suitable yardstick for assessing the adequacy of different dialytic techniques $[20,26]$. One of such evaluation was carried out in complementary to a mathematical model that takes into account the urea clearance in a single hemodialysis session $\left\{K t / V_{\text {urea }}\right.$ : parameter for classification of kidney disease outcomes quality initiative [118]; where $K=$ dialyzer clearance of urea, $t=$ dialysis time and $V=$ volume of distribution of urea $\}$ in the course of depuration against large and small toxins in uremic patients [26].

\section{Rheumatoid arthritis}

Meta-analysis of epidemiological surveys involving PCR based assays showed that there was a relationship between GSTM1, GSTT1 and GSTP1 polymorphisms and pathogenesis of rheumatoid arthritis in Asian or European population [119-122]. On the contrary, casecontrol study approach using amplification refractory mutation system-PCR and mPCR assays revealed that only the GSTM1 polymorphism was associated with rheumatoid arthritis risk in a sample of the Iranian population [123]. Toxicological assessments showed that GSTM1-null and GSTT1-null genotypes alongside GSTP1 (Ile105 $\rightarrow$ Val114) polymorphism display low GST detoxification capacity, which are potential risk factors that influence susceptibility to rheumatoid arthritis and impact on the outcome of the disease [124]. The therapeutic response to non-steroidal anti-inflammatory drugs (e.g., D-penicillamine) in rheumatoid arthritis may be influenced by GST polymorphisms. Studies according to Layton et al., [125] showed that patients who possess the GSTM $1^{*} 0-G S T M 3^{*} A$ haplotype are significantly less likely to show beneficial response to D-penicillamine.

\section{Conclusion}

The expression of various GST isoforms in biologic systems is of relevance from clinical and toxicity standpoints and applies in renewed efforts in the eradication and control of parasitic infections. The present review showed that a survey of frequency of polymorphism and a measure of GST activity among human population groups are reliable and valuable diagnostic tools in ascertaining the prevalence and susceptibility to various forms of pathology by individuals who express such protein genotypes. Additionally, the reliability of GST activity in diagnostic pathology is underscored in pathologic conditions/disorders whose etiologies are associated with overwhelming levels of oxidative stress and failure of GST-mediated detoxification mechanisms.

\section{Acknowledgment}

The author is grateful to Mrs. Chinwendu M Chikezie for technical assistance and proof reading the manuscript.

\section{References}

1. Jacoby WB (1976) Glutathione S-transferase: A group of multifunctional detoxification proteins. John-Wiley Interscience. New York.

2. Mannervik B, Danielson UH (1988) Glutathione transferases-structure and catalytic activity. CRC Crit Rev Biochem 23: 283-337.

3. Vosa RME, Van Bladerena PJ (1990) Glutathione S-transferases in relation to their role in the biotransformation of xenobiotics. Chem Biol Interact 75: 241-265.

4. Schmidt-Krey I, Mitsuoka K, Hirai T, Murata K, Cheng Y, et al. (2000) The threedimensional map of microsomal glutathione transferase 1 at $6 \AA$ resolution. EMBO J 19: 6311-6316.

5. Raza H (2011) Dual localization of glutathione S-transferase in the cytosol and mitochondria: Implications in oxidative stress, toxicity and disease. FEBS $J$ 278: 4243-4251.

6. Harwaldt P, Rahlfs S, Becker K (2002) Glutathione S-transferase of the malaria parasite Plasmodium falciparum characterization of a potential drug target. Biol Chem 383: 821-830.

7. Deponte M, Becker K (2005) Glutathione S-transferase from malarial parasitesstructural and functional aspects. Methods Enzymol 401: 240-252.

8. Mcllwain CC, Townsend DM, Tew KD (2006) Glutathione S-transferase polymorphisms: Cancer incidence and therapy. Oncogene 25: 1639-1648.

9. Bostwick DG, Meiers I, Shanks JH (2007) Glutathione S-transferase: Differential expression of $\alpha, \mu$, and $\pi$ isoenzymes in benign prostate, prostatic intraepithelial neoplasia, and prostatic adenocarcinoma. Human Pathol 38: 1394-1401.

10. Moradi M, Mojtahedzadeh M, Mandegari A, Soltan-Sharifi MS, Najafi A, et al. (2009) The role of glutathione S-transferase polymorphisms on clinical outcome of ALI/ARDS patient treated with N-acetylcysteine. Respir Med 103: 434-441.

11. Mangoyi R, Hayeshi R, Ngadjui B, Ngandeu F, Bezabih M, et al. (2010) Glutathione transferase from Plasmodium falciparum-interaction with malagashanine and selected plant natural products. J Enzyme Inhib Med Chem 25: 854-862.

12. Yang Y, Xu Y, Lick SD, Awasthi YC, Boora PJ (2008) Endothelial glutathione $S$-transferase A4-4 protects against oxidative stress and modulates iNOS expression through NF-kB translocation. Toxicol Appl Pharmacol 230:187-196.

13. Ahuja $P$, Caffé AR, Ahuja S, Ekström P, van Veen T (2005) Decreased glutathione transferase levels in rd1/rd1 mouse retina: Replenishment protects photoreceptors in retinal explants. Neurosci 131: 935-943.

14. Tew KD, Manevich Y, Grek C, Xiong Y, Uys J, et al. (2011) The role of glutathione S-transferase $\mathrm{P}$ in signaling pathways and S-glutathionylation in cancer. Free Radic Biol Med 51: 299-313.

15. Boyland E, Chasseaud LF (1969) The role of glutathione and glutathione $S$-transferase in mercapturic acid biosynthesis. Adv Enzymol Relat Areas Mol Biol 32: 73-219.

16. Ketley JN, Habig WH, Jacoby WB (1975) Binding of non-substrate ligand to glutathione $S$-transferase from human erythrocyte. Arch Biochem Biophys 188: 287-293.

17. Awasthi YC, Garg HJ, Dao DD, Partridge CA, Srivastiva SK (1981) Enzymatic conjugation with 1-chloro-2,-4-dinitrobenzene. The fate of glutathione conjugates in erythrocytes and the effect of glutathione depletion on hemoglobin. Blood 58: 733-773.

18. Hayes JD, Pulford DJ (1995) The glutathione S-transferase super family Regulation of GST and the contribution of the isoenzymes to cancer chemoprotection and drug resistance. Crit Rev Biochem Mol Biol 30: 445-600.

19. Harvey JW, Beutler E (1982) Binding of heme by glutathione S-transferase: The first step in mercapturic acid formation. J Biol Chem 245: 7130-7139.

20. Galli F, Rovidati S, Benedettis S, Buoncristiani U, Covarelli C, et al. (1999) Over expression of erythrocyte glutathione $S$-transferase in uremia and dialysis. Clin Chem 45: 1781-1788.

21. Marrs KA (1996) The functions and regulation of glutathione S-transferase in plants. Annu Rev Plant Physiol Plant Mol Biol 47: 127-158.

22. Hiller N, Fritz-Wolf K, Deponte M, Wende W, Zimmerman H, et al. (2006) Plasmodum falciparum glutathione $S$-transferase-structural and mechanistic studies on ligand binding and enzyme inhibition. Protein Sci 15: 281-289. 
23. Boyer TD, Oslen E (1991) Role of glutathione S-transferase in heme transport Biochem Pharmacol 42: 188-190.

24. Oakley AJ, Lo Bellow M, Nucceteli M, Mazzetti AP, Parker MW (1999) The ligandin (non-substrate) binding site of human pi class glutathione transferase is located in the electrophile binding sited (H-Site). J Mol Biol 291: 913-926.

25. Kamisaka K, Habig WH, Ketley JN, Arias IM, Jacoby WB (1975) Multiple forms of human glutathione $S$-transferase and their affinity for bilirubin. Eur J Biochem 60: $153-161$

26. Noce A, Ferrannini M, Fabrini R, Bocedi A, Dessì M, et al. (2012) Erythrocyte glutathione transferase: A new biomarker for hemodialysis adequacy, overcoming the $\mathrm{Kt} / \mathrm{V}$ (urea) dogma? Cell Death Dis 3: e377.

27. Litwack G, Ketterer B, Arias IM (1971) Ligandin: A hepatic protein, which binds steroids, bilirubin, carcinogens and a number of exogenous organic anions. Nature 234: 466-467.

28. Adler V, Yin Z, Fuchs SY, Benezra M, Rosario L, et al. (1999) Regulation of JNK signaling by GSTp. EMBO J 18: 1321-334.

29. Chasseaud LF (1979) Determination of thioesters as biochemical markers for monitoring exposure to potential toxicant. Academic Press Limited. New York.

30. Anosike EO, Uwakwe AA, Monanu MO, Ekeke GI (1991) Studies on human erythrocyte glutathione $\mathrm{S}$-transferase from $\mathrm{HbAA}, \mathrm{HbAS}$ and $\mathrm{HbSS}$ subjects. Biochem Biomed Acta 50: 1051-1056.

31. Ayalogu EO, Uwakwe AA, Abiam UA (2000) Effect of fansidar and chloroquine on erythrocyte glutathione S-transferase (E.C:2.5.1.18) activity; total plasma protein and blood hemoglobin concentration of rat. J Appl Sci Environ Manag 4: 83-89.

32. Board P, Coggan M, Johnston P, Ross V, Suzuki T, et al. (1990) Genetic heterogeneity of the human glutathione transferases; a complex of gene families. Pharmacol Ther 48: 357-369.

33. Habig WH, Pabst MJ, Jacoby WB (1974) Glutathione S-transferases: The firs enzymatic step in mercapturic acid formation. J Biol Chem 249: 7130-7139.

34. Muller S (2004) Redox and antioxidant systems of the malaria parasite: Plasmodium falciparum. Mol Microbiol 53: 1291-1305.

35. Jortzik E, Becker K (2012) Thioredoxin and glutathione systems in Plasmodium falciparum. Int J Med Microbiol 302: 187-194.

36. Muller S (2015) Role and regulation of glutathione metabolism in Plasmodium falciparum. Mol 20: 10511-10534.

37. van Rossum AJ, Jefferies JR, Rijsewijk FAM, LaCourse EJ, Teesdale-Spittle $P$ et al. (2004) Binding of hematin by a new class of glutathione transferase from the blood-feeding parasitic nematode Haemonchus contortus. Infect Immun 72 2780-2790.

38. Vibanco-Pérez N, Landa-Piedra A (1998) Glutathione S-transferase in helminth parasites. Rev Latinoam Microbiol 40: 73-85

39. Tripathi T, Rahlfs S, Becker K, Bhakuni V (2007) Glutathione mediated regulation of oligomeric structure and functional activity of Plasmodium falciparum glutathione S-transferase. BMC Struct Biol 7: 67.

40. Awasthi YC, Sharma R, Singhal SS (1994) Human glutathione S-transferase. Int J Biochem 26: 295-308.

41. Wilce MC, Parker MW (1994) Structure and function of glutathione S-transferases. Biochem Biophys Acta 1205: 1-18.

42. Wilce MCJ, Board PG, Feil SC, Parker MW (1995) Crystal structure of a thetaclass glutathione transferase. EMBO J 14: 2133-2143.

43. Coughlin SS, Hall IJ (2002) Glutathione S-transferase polymorphisms and risk of ovarian cancer: A HuGE review. Genet Med 4: 250-257.

44. Jakobsson PJ, Morgenstern R, Mancini J, Ford-Hutchinson A, Persson B (2000) Membrane-associated proteins in eicosanoid and glutathione metabolism (MAPEG). A widespread protein superfamily. Am J Respir Crit Care Med 161 S20-S24.

45. Hayes JD, Flanagan JU, Jowsey IR (2005) Glutathione S-transferases. Ann Rev Pharmacol Toxicol 45: 51-88.

46. Hebert H, Jegerschöld C (2007) The structure of membrane associated proteins in eicosanoid and glutathione metabolism as determined by electron crystallography. Curr Opin Struct Biol 17: 396-404.
47. Board PG, Baker RT, Chelvanayagan G, Jermin LS (1997) Zeta, a nove class of glutathione transferases in a range of species from plants to humans. Biochem J 238: 920-935

48. Takikawa H, Kaplowitz N (1988) Comparison of the binding sites of GSH $S$-transferases of the $\mathrm{Ya}$ - and $\mathrm{Yb}$ - subunits classes: Effect of glutathione on the binding of bile acids. J Lipid Res 29: 279-286.

49. Marcus CH, Habig WH, Jacoby NB (1978) Glutathione S-transferase from human erythrocyte. Arch Biochem Biophys 38: 287-293.

50. Baranova H, Bothorishvilli R, Canis M, Albuisson E, Perriot S, et al. (1997) Glutathione S-transferase M1 gene polymorphism and susceptibility to endometriosis in a French population. Mol Human Reprod 3: 775-780.

51. Kavishe RA, Koenderink JB, McCall MB, Peters WH, Mulder B, et al. (2006) Severe Plasmodium falciparum malaria in Cameroon: Associated with the glutathione S-transferase M1 null genotype. Am J Trop Med Hyg 75: 827-829.

52. Karam RA, Pasha HF, El-Shal AS, Rahman HMA, et al. (2012) Impact of glutathione S-transferase gene polymorphisms on enzyme activity, lung function and bronchial asthma susceptibility in Egyptian children. Gene 497: 314-319.

53. Watson MA, Stewart RK, Smith GB, Massey TE, Bell DA (1998) Human glutathione $S$-transferase $\mathrm{P} 1$ polymorphisms: relationship to lung tissue enzyme activity and population frequency distribution. Carcinogenesis 19: $275-$ 280 .

54. Bolt HM, Thier R (2006) Relevance of the deletion polymorphisms of the glutathione S-transferases GSTT1 and GSTM1 in pharmacology and toxicology. Curr Drug Metab 7: 613-628.

55. Zimniak P, Nanduri B, Pikula S, Bandorowicz-Pikula J, Singhal SS, et al (1994) Naturally occurring human glutathione S-transferase GSTP1-1 isoforms with isoleucine and valine in position 104 differ in enzymic properties. Eur J Biochem 224: 893-899.

56. Srivastava P, Puri SK, Kamboj KK, Pandey VC (1999) Glutathione S-transferase activity in malarial parasites. Trop Med Int Health 4: 251-254.

57. Sohail M, Kaul A, Raziuddin M, Adak T (2007) Decreased glutathione $S$-transferase activity: Diagnostic and protective role in vivax malaria. Clin Biochem 40: 377-382.

58. Neupane DP, Majhi S, Chandra L, Rijal S, Baral N (2008) Erythrocyte glutathione status in human visceral Leishmaniasis. Indian J Clin Biochem 23: 95-97.

59. Becker K, Tilley L, Vennerstrom JL, Roberts D, Rogerson S, Ginsburg H (2004) Oxidative stress in malaria parasite infected erythrocytes: host- parasite interactions. Int J Parasitol 34:163-189.

60. Chikezie PC, Chikezie CM, Uwakwe AA, Monago CC (2009) Comparative study of glutathione $S$-transferase activity of three human erythrocyte genotypes infected with Plasmodium falciparum. J Appl Sci Environ Manag 13: 13-18.

61. Szarka CE, Pfeiffer GR, Hum ST, Everley LC, Balshem AM, et al. (1995) Glutathione S-transferase activity and glutathione S-transferase mu expression in subjects with risk for colorectal cancer. Cancer Res 55: 2789-2793.

62. Wrigley EC, McGown AT, Buckley H, Hall A, Crowther D (1996) Glutathione $S$-transferase activity and isoenzyme levels measured by two methods in ovarian cancer, and their value as markers of disease outcome. $\mathrm{Br} \mathrm{J}$ Cancer 73: 763-769.

63. Chen YK, Lin L-M (1997) Evaluation of glutathione S-transferase activity in human buccal epithelial dysplasias and squamous cell carcinomas. Int J Oral Maxillofac Surg 26: 205-209.

64. Naidu KA, Nasir A, Pinkas H, Kaiser HE, Brady P, et al. (2003) Glutathione $S$-transferase pi expression and activity is increased in colonic neoplasia. In Vivo 17: 479-482.

65. Akçay T, Dinçer Y, Alademir Z, Aydınlı K, Arvas M, et al. (2005) Significance of the $\mathrm{O}^{6}$-methylguanine-DNA methyltransferase and glutathione $S$-transferase activity in the sera of patients with malignant and benign ovarian tumors. Eur $\mathrm{J}$ Obstet Gynecol Reprod Biol 119: 108-113.

66. Casson, AG, Zheng Z, Porter GA, Guernsey DL (2006) Genetic polymorphism of microsomal epoxide hydroxylase and glutathione $S$-transferases M1, $\mathrm{T} 1$ and $\mathrm{P} 1$, interactions with smoking, and risk for esophageal (Barrett) adenocarcinoma. Cancer Detect and Prev 30: 423-431.

67. Meng X, Liu Y, Liu B (2014) Glutathione S-transferase M1 null genotype metaanalysis on gastric cancer risk. Diagn Pathol 9: 122. 
68. Forrester LM, Hayes JD, Millis R, Barnes D, Harris AL, et al. (1990) Expression of glutathione $S$-transferases and cytochrome P450 in normal and tumor breast tissue. Carcinog 11: 2163-2170

69. Ghazaly GD, Zakahary MM, El-aziz MA, Mahmoud AM, Carretero P, et al (1997) Expression of glutathione S-transferase activity and glutathione content in squamous cell carcinoma of bladder associated with Schistosomiasis in a population in Egypt. Scand J Urol Nephrol 31: 43-47.

70. Engel LS, Taioli E, Pfeiffer R, Garcia-Closas M, Marcus PM, et al. (2002) Pooled analysis and meta-analysis of glutathione S-transferase M1 and bladder cancer: A HuGE review. Am J Epidemiol 2002; 156: 95-109.

71. Crump C, Chen C, Appelbaum FR, Kopecky KJ, Schwartz SM, et al. (2000) Glutathione S-transferase theta 1 gene deletion and risk of acute myeloid leukemia. Cancer Epidemiol Biomark Prev 9: 457-460.

72. Lee EJ, Wong JY, Yeoh PN, Gong NH (1995) Glutathione S-transferase theta (GSTT1) genetic polymorphism among Chinese, Malays and Indians in Singapore. Pharmacogenetics 5: 332-334.

73. Srivastava R, Sharma R, Mishra S, Singh RB (2011) Biochemical and molecular biological studies on oral cancer: An overview. Open Nutraceut J 4: 180-188.

74. Tew KD (1994) Glutathione-associated enzymes in anticancer drug resistance. Cancer Res 54: 4313-4320.

75. Mulder TPJ, Court DA, Peters WHM (1999) Variability of glutathione $S$-transferase $\alpha$ in human liver and plasma. Clin Chem 45: 355-359.

76. Beckett GJ, Hayes JD (1993) Glutathione S-transferases: biomedical applications. Adv Clin Chem 30: 281-380.

77. Yukihiko A, Kazuomi H, Yoshiro T, Misuzu T, Yasuhiro O, et al. (1980) Serum glutathione S-transferase activity in liver diseases. Clin Chim Acta 106: 243 255.

78. Moatamedi PL, Farahnak A, Molaei RM, Golmohamadi T, Eshraghian M (2014) Activity assay of glutathione S-transferases (GSTs) enzyme as a diagnostic biomarker for liver hydatid cyst in Vitro. Iran J Public Health 43: 994-999.

79. Thorburn D, Bird GLA, Spence E, MacSween RNM, Mills PR (1996) a-Glutathione $S$-transferase levels in chronic hepatitis $C$ infection and the effect of a-interferon therapy. Clin Chim Acta 253: 171-180.

80. Weng Z, Wang K, Li H, Shi Q (2015) A comprehensive study of the association between drug hepatotoxicity and daily dose, liver metabolism, and lipophilicity using 975 oral medications. Oncotarget 6: 17031-17038.

81. Rattenbury JM, Taylor CJ, Heath PK, Howie AF, Beckett GJ (1995) Serum glutathione S-transferase B1 activity as an index of liver function in cystic fibrosis. J Clin Pathol 48: 771-774.

82. Afrand M, Bashardoost N, Sheikhha MH, Afkhami-Ardekani M (2015) Association between glutathione S-transferase GSTM1-T1 and P1 polymorphisms with metabolic syndrome in Zoroastrians in Yazd, Iran. Iran J Public Health 44: 673-682.

83. Santl LM, Letonja M, Ikolajević-Starcević JN, Petrovic D (2012) Association of manganese superoxide dismutase and glutathione $S$-transferases genotypes with carotid atherosclerosis in patients with diabetes mellitus type 2. Int Angio 31: 33-41.

84. de Waart FG, Kok FJ, Smilde TJ, Hijmans A, Wollersheim H, et al. (2001) Effect of glutathione $S$-transferase M1 genotype on progression of atherosclerosis in lifelong male smokers. Atheroscler 158: 227-231.

85. Park J-H, Ahmed El-Sohemy A, Cornelis MC, Kim H-A, Kim S-Y, et al. (2004) Glutathione S-transferase M1, T1, and P1 gene polymorphisms and carotid atherosclerosis in Korean patients with rheumatoid arthritis. Rheumatol Int 24: 157-463.

86. Xu Y, Gong B, Yang Y, Awasthi YC, Boo PJ (2010) Adenovirus-mediated overexpression of glutathione $S$-transferase mitigates transplant arteriosclerosis in rabbit carotid allografts. Transplant 89: 409-416.

87. Amer MA, Ghattas MH, Abo-EIMatty DM, Abou-El-Ela SH (2012) Evaluation of glutathione S-transferase P1 genetic variants affecting type-2 diabetes susceptibility and glycemic control. Arch Med Sci 8: 631-636.

88. Pinheiro DS, Filho CR, Mundim CA, Junior PdM, Ulhoa CJ, et al. (2013) Evaluation of glutathione S-transferase GSTM1 and GSTT1 deletion polymorphisms on type-2 diabetes mellitus risk. Plos ONE 8: e76262.

89. Rasheed MN, Hasan OM, Mahmood AS (2015) Association of glutathione
S-transferase (GSTM1, T1) gene polymorphisms with type 2 diabetes mellitus (T2DM) in the Iraqi patients. Iraqi J Biotechnol 14: 70-76.

90. Wang G, Zhang L, Li Q (2006) Genetic polymorphisms of GSTT1, GSTM1, and NQO1 genes and diabetes mellitus risk in Chinese population. Biochem Biophys Res Commun 341: 310-313.

91. Hori M, Oniki K, Ueda K, Goto S, Mihara S, et al. (2007) Combined glutathione $S$-transferase T1 and M1 positive genotypes afford protection against type 2 diabetes in Japanese. Pharmacogenomics 8: 1307-1314.

92. Amer MA, Ghattas MH, Abo-Elmatty DM, Abou-el-Ela SH (2011) Influence of glutathione S-transferase polymorphisms on type-2 diabetes mellitus risk. Genet Mol Res 10: 3722-3730.

93. Velladath SU, Das A, Kumar RKN (2011) Erythrocyte glutathione S-transferase activity in diabetics and its association with $\mathrm{HbA}_{1}$. Webmed Cent Clin Biochem 2: WMC002004.

94. Schuppe HC, Wieneke P, Donat S, Fritsche E (2000) Xenobiotic metabolism genetic polymorphisms and male infertility. Andrologia 32: 255-262.

95. Hadfield RM, Manek S, Weeks DE, Mardon HJ (2001) Linkage and association studies of the relationship between endometriosis and genes encoding the detoxification enzymes GSTM1, GSTT1 and CYP1A1. Mol Hum Reprod 7 : 1073-1078.

96. Sata F, Yamada H, Kondo T, Gong Y, Tozaki S, et al. (2003) Glutathione $S$-transferase $\mathrm{M} 1$ and $\mathrm{T} 1$ polymorphisms and the risk of recurrent pregnancy loss. Mol Hum Reprod 9: 165-169.

97. Zusterzeel PLM, Nelen WLD, Roelofs MJ, Peters WHM, Blom HJ, et al. (2000) Polymorphisms in biotransformation enzymes and the risk for recurrent early pregnancy loss. Mol Human Reprod 6: 474-478.

98. Suryanarayana V, Deenadayal M, Singh L (2004) Association of CYP1A1 gene polymorphism with recurrent pregnancy loss in the South Indian population. Hum Reprod 19: 2648-2652.

99. Polimanti R, Piacentini Sara, Lazzarin N, Vaquero E, Re MA, et al. (2012) Glutathione S-transferase genes and the risk of recurrent miscarriage in Italian women. Fertil Steril 98: 396-400.

100. Nair RR, Khanna A, Singh K (2013) Association of GSTT1 and GSTM1 polymorphisms with early pregnancy loss in an Indian population and a metaanalysis. Reprod Biomed Online 26: 313-322.

101. Chandra N, Mehndiratta M, Banerjee BD, Guleriab K, Tripathia AK (2015) Phenotypic expression and polymorphism of Glutathione S-transferase gene in materno-fetal dyads with idiopathic fetal growth restriction. J Reprod Health Med 1: 10-17.

102. Neefjes VME, Evelo CTA, Bears LGM, Blanco CE (1999) Erythrocyte glutathione $S$-transferase as a marker of oxidative stress at birth. Arch Dis Child Fetal Neonatal Ed 81: F130-F133.

103. Obolenskaya MY, Teplyuk NM, Divi RL, Poirier MC, Filimonova NB, et al. (2010) Human placental glutathione S-transferase activity and polycyclic aromatic hydrocarbon DNA adducts as biomarkers for environmental oxidative stress in placentas from pregnant women living in radioactivity- and chemically-polluted regions. Toxicol Lett 196: 80-86.

104. Boeira SP, Filho CB, Del'Fabbro L, Royes LFF, Jessé CR, et al. (2012) Possible role for glutathione $S$-transferase in the oligozoospermia elicited by acute zearalenone administration in Swiss albino mice. Toxicon 60: 358-366.

105. Quinn BA, Crane TL, Kocal TE, Best SJ, Cameron RG, et al. (1990) Protective activity of different hepatic cytosolic glutathione $S$-transferases against DNAbinding metabolites of aflatoxin B1. Toxicol Appl Pharmacol 105: 351-363.

106. Pajarinen J, Savolainen V, Perola M, Penttila A, Karhunen PJ (1996) Glutathione S-transferase- M1 'null' genotype and alcohol-induced disorders of human spermatogenesis. Int J Androl 19: 155-163.

107. Savolainen VT, Pjarinen J, Perola M, Penttilä A, Karhunen PJ (1996) Glutathione S-transferase GST M1 'null' genotype and the risk of alcoholic liver disease. Alcohol Clin Exp Res 20: 1340-1345.

108. Ladero JM, Martínez C, García-Martin E, Fernández-Arquero M, LópezAlonso G, et al. (2005) Polymorphisms of the glutathione S-transferases mu-1 (GSTM1) and theta-1 (GSTT1) and the risk of advanced alcoholic liver disease. Scand J Gastroenterol 40: 348-353.

109. Marcos M, Pastor I, Chamorro AJ, Ciria-Abad S, Gonzalez -Sarmiento R (2011) Meta-analysis: Glutathione S-transferase allelic variants are 
associated with alcoholic liver disease. Aliment Pharmacol Ther 34: 11591172.

110. Peter N, Chiramel KJ, Shivashankara AR (2013) Effect of alcohol withdraw on glutathione $S$-transferase, total antioxidant capacity and amylase in blood and saliva of alcohol-dependent males. J Clin Diagn Res 7: 797-800

111. La Vignera S, Condorelli RA, Balercia G, Vicari E, Calogero AE (2013) Does alcohol have any effect on male reproductive function? A review of literature. Asian J Androl 15: 221-225.

112. Uys JD, Mulholland PJ, Townsend DM (2014) Glutathione and redox signaling in substance abuse. Biomed Pharmacother 68: 799-807.

113. Gutowicz M, Kazmierczak B, Baranczyk-Kuzma A (2011) The influence of heroin abuse on glutathione-dependentnenzymes in human brain. Drug Alcohol Depend 113: 8-12.

114. Branten AJ, Mulder TP, Peters WH, Assmann KJ, Wetzels JF (2000) Urinary excretion of isoenzymes of glutathione $S$-transferase alpha and pi in patients with proteinuria: Reflection of the site of tubular injury. Nephron 85: 120-126.

115. Carmagnol F, Sinet PM, Rapin J, Jerome H (1981) Glutathione S-transferase of human red blood cells; assay, values in normal subjects and in two pathological circumstances hyperbilirubinemia and impaired renal function. Clin Chim Acta 117: 209-217.

116. Dessi M, Noce A, Dawood KF, Galli F, Taccone-Gallucci M, et al. (2012) Erythrocyte glutathione transferase: a potential new biomarker in chronic kidney diseases which correlates with plasma homocysteine. Amino Acids 43: $347-354$

117. Kolagal V, Karanam SA, Dharmavarapu PK, D'Souza R, Upadhya S, et al. (2009) Determination of oxidative stress markers and their importance in early diagnosis of uremia-related complications. Indian J Nephrol 19: 8-12.
118. (2000) Clinical practice guidelines for nutrition in chronic renal failure. $\mathrm{K}$ DOQI, National Kidney Foundation. Am J Kidney Dis 35: S1-S140.

119. Mattey D, Hassell A, Plant M, Dawes P, Ollier W, et al. (1999) Association of polymorphism in glutathione $S$-transferase loci with susceptibility and outcome in rheumatoid arthritis: comparison with the shared epitope. Ann Rheum Dis 58: 164-168.

120. Morinobu S, Morinobu A, Kanagawa S, Hayashi N, Nishimura K (2006) Glutathione S-transferase gene polymorphisms in Japanese patients with rheumatoid arthritis. Clin Exper Rheumatol 24: 268-273.

121. Song GG, Bae S-C, Lee YH (2012) The glutathione S-transferase M1 and P1 polymorphisms and rheumatoid arthritis: a meta-analysis. Mol Biol Rep 39: 10739-10745.

122. Ji JD, Lee WJ (2013) Association between the polymorphisms of glutathione $S$-transferase genes and rheumatoid arthritis: A meta-analysis. Gene 521: 155-159.

123. Hashemi M, Eskandari-Nasab E, Zakeri Z, Atabaki M, Rezaei H, et al. (2012) A possible relationship between polymorphisms of glutathione $S$-transferase M1, P1 and T1 genes and rheumatoid arthritis in Zahedan, Southeast Iran. Turk J Rheumatol 27: 253-257.

124. Yun BR, El-Sohemy A, Cornelis MC, Bae SC (2005) Glutathione S-transferase M1, T1, and P1 genotypes and rheumatoid arthritis. J Rheumatol 32: 992 997.

125. Layton MA, Jones PW, Alldersea JE, Strange RC, Fryer AA et al. (1999) The therapeutic response to D-penicillamine in rheumatoid arthritis: influence of glutathione S-transferase polymorphisms. Rheumatol 38: 43-47. 